\title{
Wheezes may lead you wrong
}

Tolosa Morales F.1, Amador García I. ${ }^{1}$, Espinosa Domínguez M.E. ${ }^{1}$, León San Segundo T. ${ }^{1}$, Horas Barrera C. ${ }^{1}$, Rodríguez González I.P. ${ }^{1}$

${ }^{1}$ Hospital Universitario Nuestra Señora de la Candelaria, Dept of Anaesthesiology, Santa Cruz de Tenerife, (Spain). fatimatolosa@hotmail.com

\section{"A case of tracheal stenosis and dilated cardiomyopathy in a 35-year-old woman misdiagnosed with asthma"}

\section{Case Report:}

A middle-age woman was transferred to our hospital experiencing dyspnea with no improvement after bronchodilators. She suffered from leukemia treated with chemotherapy and asthma.

Due to important hypoxemia a TC scan was done showing a multinodular goiter that was compressing $75 \%$ of the tracheal lumen. A total thyroidectomy was performed.

Tracheal intubation was guided by fibrobronchoscopy, but low cardiac output signs were noticed during the procedure and in our PostAnesthesia Care Unit.

We started hemodynamic support with norepinephrine and dobutamine infusions and hemodynamic monitoring with PiCCO. Echocardiography showed dilated ventricles and $30 \%$ ejection fraction, while chest $\mathrm{x}$ ray showed grade 3 cardiomegaly.

Furosemide, spironolactone and levosimendan infusion were initiated, 24 hours later, no hemodynamic support was required.

The patient was discharged to the cardiology department 4 days after surgery.

\section{Discussion:}

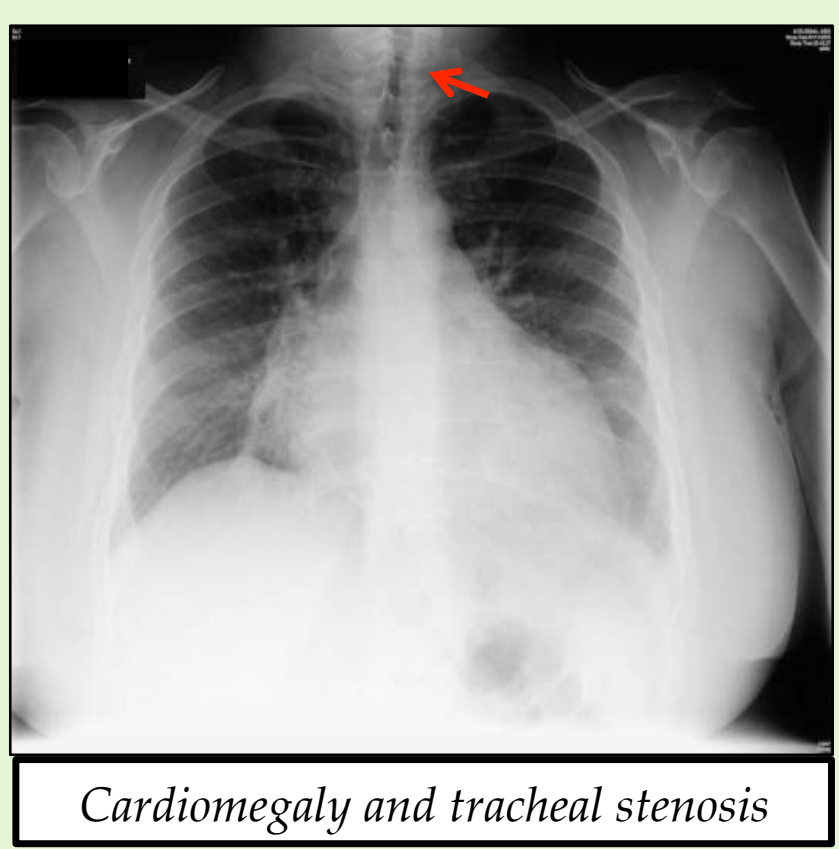

Even with cardiomegaly and symptoms due to a decompensated heart failure, the patient was diagnosed with asthma, her age being a confusing factor and goiter worsening her respiratory failure.

We diagnosed it with echocardiography and we used transpulmonary thermodilution for assessment of cardiac function.

We started dobutamine and norepinephrine in order to solve low cardiac output (1). Levosimendan infusion of $0.1 \mathrm{mg} / \mathrm{kg} / \mathrm{min}$ for $24 \mathrm{~h}$ improved general and pulmonary hemodynamics.

Dilated Cardiomyopathy is characterized by a dysfunction of one or both ventricles, chemotherapy or hyperthyroidism being the possible etiology in this patient. Newly identified targets, such as calcium sensitizing, improve prognosis and reduce mortality (2).

\section{Learning points:}

- Dilated Cardiomyopathy may present de novo in people without known cardiac dysfunction, we should suspect it when cardiomegaly and dyspnea are present

- Echocardiography is an important tool for urgent diagnosis

- Levosimendan is a potential drug for the treatment of decompensated heart failure

- Fixation errors could lead to a misdiagnosis with fatal consecuences

\section{References:}

1. M. Merlo et al (2015): Clinical management of dilated cardiomyopathy: current knowledge and future perspectives, Expert Rev Cardiovasc Ther, DOI: 10.1586/14779072.2016.1125292. 2. P. Pollesello et al (2015): Calcium sensitizers: What have we learned over the last 25 years? Int J Cardiol, 203 (2016) 543-548. 